\title{
Congenital non-bullous ichthyosiform erythroderma
}

INSERM

\section{Source}

INSERM. (1999). Orphanet: an online rare disease and orphan drug data base. Congenital non-bullous ichthyosiform erythroderma. ORPHA:79394

Congenital ichthyosiform erythroderma (CIE) is a variant of autosomal recessive congenital ichthyosis (ARCl; see this term), a rare epidermal disease, characterized by fine, whitish scales on a background of erythematous skin over the whole body. 